\title{
Angiotensin Receptor Blockers Versus Angiotensin Converting Enzyme Inhibitors for the Treatment of Arterial Hypertension and the Role of Olmesartan
}

\author{
Stefano Omboni (D) - Massimo Volpe (D)
}

Received: October 2, 2018 / Published online: December 27, 2018

(C) The Author(s) 2018

\begin{abstract}
Blood pressure lowering by all classes of antihypertensive drugs is accompanied by significant reductions of stroke and major cardiovascular (CV) events. Drugs acting on the renin-angiotensin-aldosterone system, such as angiotensin converting enzyme inhibitors (ACEIs) and angiotensin receptor blockers (ARBs), showed similar benefit on major CV events to other antihypertensive medications. In real-world practice, ARBs reduced by $10 \%$ the incidence of CV mortality, non-fatal myocardial
\end{abstract}

Enhanced digital features To view enhanced digital features for this article go to https://doi.org/10.6084/ m9.figshare.7423655.

S. Omboni $(\square)$

Clinical Research Unit, Italian Institute of

Telemedicine, Varese, Italy

e-mail: stefano.omboni@iitelemed.org

S. Omboni

Scientific Research Department of Cardiology,

Science and Technology Park for Biomedicine,

Sechenov First Moscow State Medical University,

Moscow, Russian Federation

M. Volpe

Chair and Division of Cardiology, Department of

Clinical and Molecular Medicine, Faculty of

Medicine and Psychology, Sant'Andrea Hospital,

University of Rome Sapienza, Rome, Italy

M. Volpe

IRCCS Neuromed, Pozzilli, Isernia, Italy infarction, non-fatal stroke and provided superior protection against $\mathrm{CV}$ events than ACEIs in high-risk patients. Despite similar antihypertensive properties and a favourable safety profile for both ACEIs and ARBs, evidence indicates that patients treated with ARBs have lower rates of withdrawal for adverse events and greater persistence to therapy than those treated with ACEIs. Among ARBs, olmesartan is one of the latest generation compounds introduced in clinical practice for treating hypertension: head-to-head comparative trials suggest that the efficacy of olmesartan is superior to that of commonly prescribed ACEIs (ramipril and perindopril). The drug, administered as a monotherapy or in combination with a dihydropyridine calcium channel blocker or a thiazide diuretic, has proved to be effective in maintaining blood pressure stability over $24 \mathrm{~h}$, with a favourable safety profile and low discontinuation rates. These properties are pivotal for considering olmesartan as a useful antihypertensive agent especially for high-risk patients (e.g. elderly, diabetics, patients with metabolic syndrome).

Funding: Article preparation and open access fee were funded by Menarini International Operations Luxembourg S.A. (M.I.O.L.)

Keywords: Ambulatory blood pressure; Angiotensin converting enzyme inhibitors; Angiotensin receptor blockers; Arterial 
hypertension; Blood pressure; Blood pressure variability; Cardiology; Olmesartan

\section{INTRODUCTION}

Worldwide, the burden of cardio-metabolic risk factors becomes the most important cause of mortality and years of life lost [1]. Raised levels of blood pressure (BP), body mass index, blood glucose and cholesterol are responsible for more than $60 \%$ of global deaths from cardiovascular disease (CVD), chronic kidney disease and diabetes, with hypertension having a major impact [2]. The rise in systolic blood pressure (SBP) has a greater effect on angina, myocardial infarction and peripheral artery disease, whereas increased diastolic blood pressure (DBP) is mainly associated with abdominal aortic aneurysm [3]. Hypertension is also the main cause of stroke, congestive heart failure and atrial fibrillation [4].

The benefits of treatments aimed to lower BP for CVD prevention are well established. A $10-\mathrm{mmHg}$ decrease in SBP reduces the risk of major CVD events by $20 \%$, coronary heart disease by $17 \%$, stroke by $27 \%$, heart failure by $28 \%$ and all-cause mortality by $13 \%$ [5], while a decrease in DBP has been linearly related to a lower risk of recurrent stroke $(p=0.026)$ and allcause mortality $(p=0.009)$ [6].

The effects of BP lowering are broadly similar even in the presence of concomitant comorbidities or previous CVDs, coronary heart disease or cerebrovascular disease [5]. These findings highlight the importance of a tight and persistent BP control, which is increasingly being considered as the most essential therapeutic strategy for effective secondary CVD prevention [6].

Controlling and lowering BP is per se functional to reduce $\mathrm{CV}$ risk, independently of the antihypertensive approaches used [7] and produces a significant outcome improvement in all hypertension grades, in patients at high risk for the presence of diabetes mellitus and in those with a history of previous CV events [8-10].
Fig. 1 Relative risk (RR) reduction (and 95\% confidence intervals) of various outcomes in trials of blood pressure (BP) lowering by different classes of drugs: diuretics (a), centrally acting drugs (b), beta-blockers (c), calcium channel blockers (d), angiotensin converting enzyme (ACE) inhibitors (e), angiotensin receptor blockers (f). SBP systolic blood pressure, DBP diastolic blood pressure. Redrawn from Zanchetti A, Thomopoulos C, Parati G. Randomized controlled trials of blood pressure lowering in hypertension: a critical reappraisal. Circ Res. 2015;116(6): 1058-73. https://www.ahajournals.org/doi/full/10.1161/ CIRCRESAHA.116.303641 ?url_ver=Z39.88-2003\&rfr_id= ori\%3Arid\%3Acrossref.org\&rfr_dat=cr_pub\%3Dpubmed

Treatments aimed at lowering BP may be important in reducing CVD risk even in individuals with normal or high normal BP [11].

All classes of antihypertensive drugs have been shown to significantly reduce the risk of stroke and major CV events: however, some classes of drugs such as those acting on the renin-angiotensin-aldosterone system (RAAS) have proved to be particularly favourable in terms of efficacy and safety and for this reason are among the most popular, widely used and recommended antihypertensive medications [4]. In this review, we present and discuss the current evidence from randomized controlled trials of the clinical effectiveness of the two most representative classes of RAAS, namely angiotensin converting enzyme inhibitors (ACEIs) and angiotensin receptor blockers (ARBs). Attention will be focused on metaanalyses of direct comparative studies, which allow a more robust evaluation of potential differences in efficacy and safety between the two drug classes. Results of recent head-to-head trials of olmesartan, an ARB known for having the longest half-life among the ARBs, vs. two ACEIs (ramipril and perindopril), will be presented with the aim of providing updated evidence from the literature of the efficacy and safety of the most popular and studied among the ARBs.

This article is based on previously conducted studies and does not contain any studies with human participants or animals performed by any of the authors. 


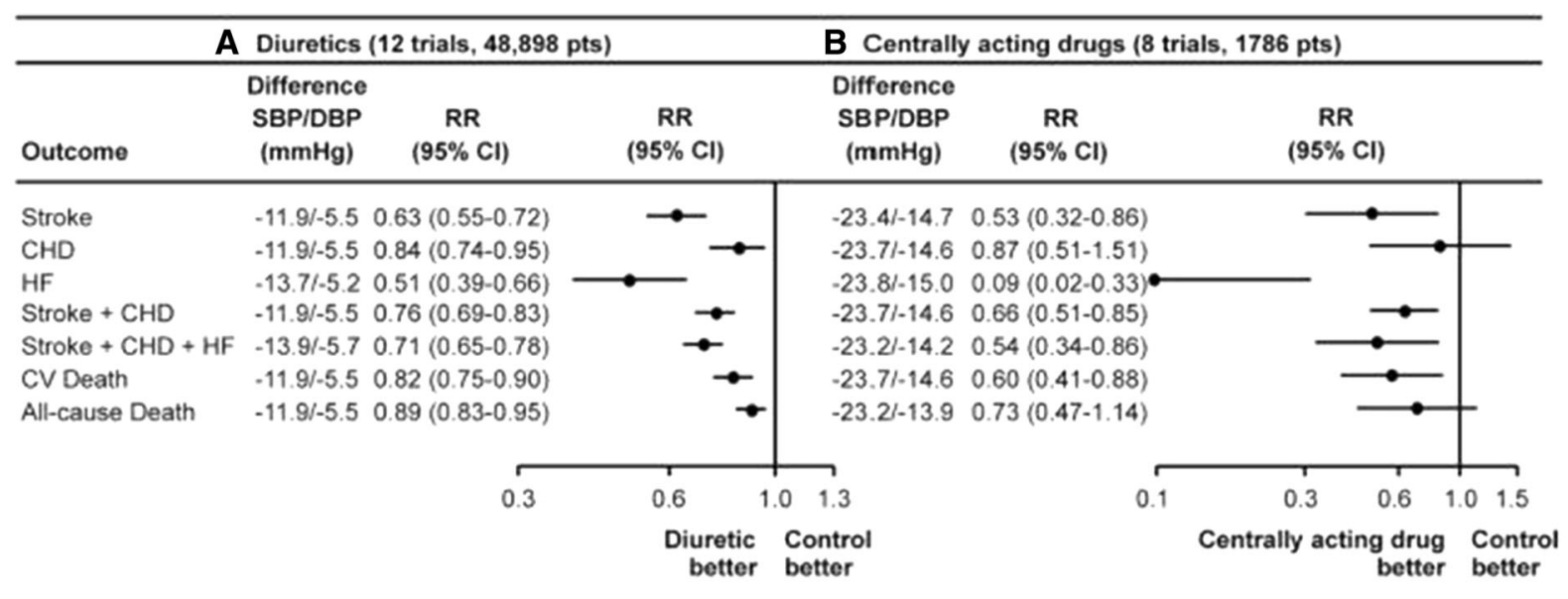

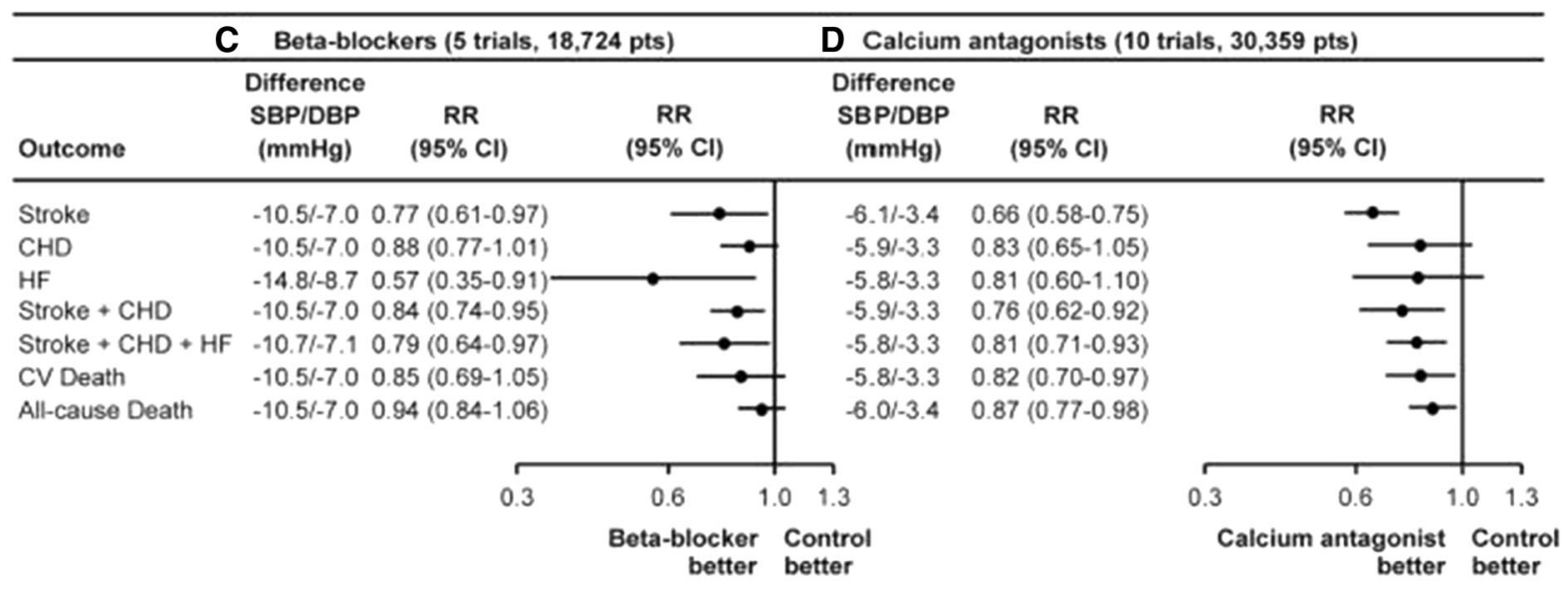

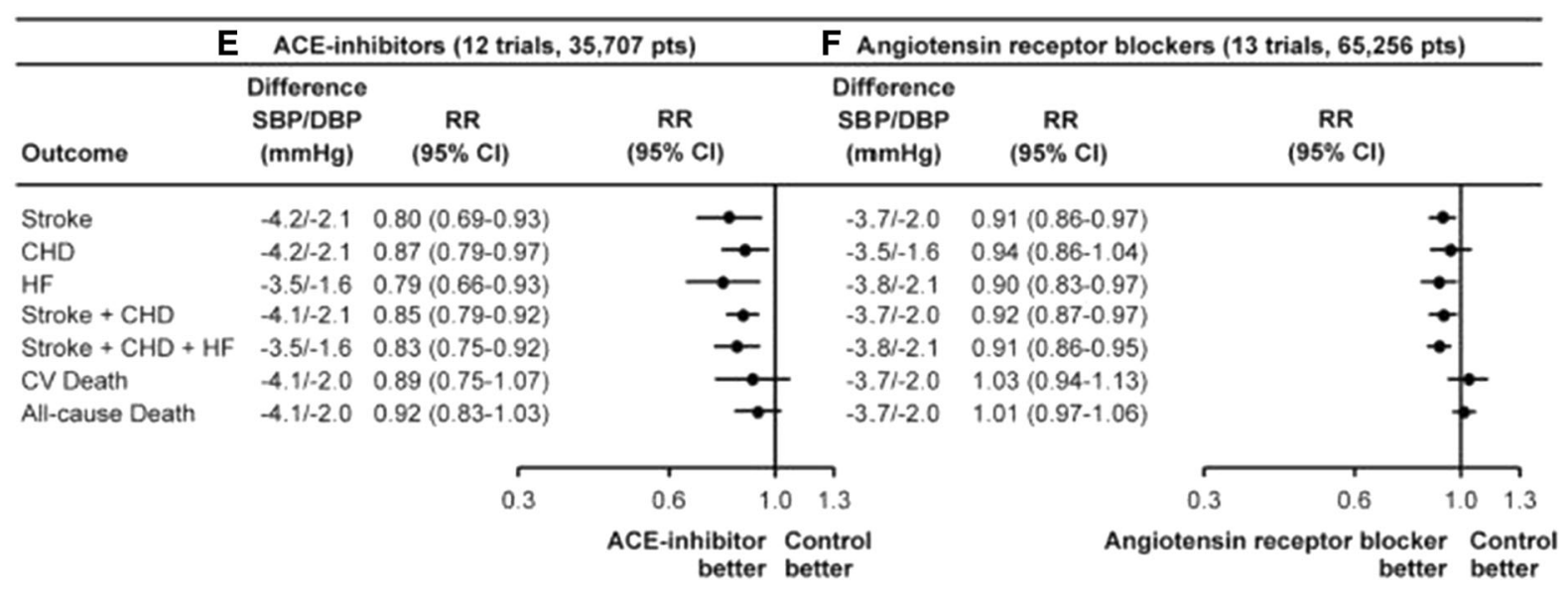




\section{ANGIOTENSIN RECEPTOR BLOCKERS AND ANGIOTENSIN CONVERTING ENZYME INHIBITORS IN THE TREATMENT OF HYPERTENSION}

As shown in Fig. 1, in large randomized controlled trials ACEIs and ARBs showed benefits on major CV events comparable to other antihypertensive medications, but less pronounced effects on CV and all-cause mortality [7]. This might be explained by the fact that trials of ACEIs and ARBs have been performed more recently than trials of other antihypertensive agents (e.g. thiazide diuretics), and RAAS blockers tended to be compared to other drug regimens rather than to placebo, hence resulting in smaller BP reductions and generally no substantial mortality benefit.

Current guidelines on the management of arterial hypertension recommend ACEIs and ARBs as first choice drugs for initiation and maintenance of antihypertensive treatment, preferably in combination with a calcium channel blocker or diuretic $[4,12]$. In addition to their antihypertensive effect, both ACEIs and ARBs exhibit other biological properties, which contribute to prevent diabetes and improve outcomes in chronic heart failure. ACEIs and ARBs are indicated in previous CVDs, such as myocardial infarction and stroke, left ventricular hypertrophy and dysfunction and in the presence of renal disease at any stage or metabolic syndrome. They are contraindicated in patients with bilateral renal stenosis, in the presence of hyperkalaemia and during pregnancy (Table 1).

Although the effect on BP lowering is similar among antihypertensive agents, some differences in the efficacy are reported in clinical practice. The differences can be partially ascribed to higher adherence and improved quality of life observed during ACEI and ARB treatments, compared to calcium channel blockers, diuretics or beta-blockers. Adherence or discontinuation is often the consequence of undesirable side effects, which are peculiar for each drug class: diuretics, for example, can cause frequent micturition, erectile dysfunction, fatigue and muscle cramps or, in other circumstances, they can produce metabolic and electrolyte abnormalities that may lead physicians to discontinue them [13].

The lower rate of adverse events and the perception of health benefit from the treatment add up to potential psychotropic effects that have been described in RAAS blockers. A recent meta-analysis indicates that treatment of healthy adults with hypertension with ACEIs or ARBs is associated with improved mental health quality of life, although this was a secondary outcome in the included studies and thus the benefit may only be hypothesized [14].

ARBs and ACEIs are associated also with a lower risk to develop new-onset diabetes mellitus with ranking probabilities of $79.8 \%$ and $72.8 \%$, respectively, while beta-blockers and calcium channel blockers may significantly increase this risk [beta-blockers: odds ratio, 2.18 (95\% confidence intervals, 1.36-3.50); calcium channel blockers: odds ratio, 1.16 (1.05-1.29)] [15]. The relationship between antihypertensive treatment and diabetes onset has not been completely understood, and it may be related to glucose tolerance, differently induced by each drug class [15]. RAAS blockade promotes the recruitment and differentiation of adipocytes via angiotensin II type 1, thus improving the effect of peripheral insulin and insulin secretion; this implies the prevention in diabetes mellitus onset [15].

Although medication for hypertension has been well established, many well-controlled hypertensive patients still suffer from atrial fibrillation. RAAS promotes atrial fibrosis, atrial electrophysiological and structural remodelling, and it may lead to atrial fibrillation recurrence [16]. Blocking RAAS may attenuate the deleterious effects of cardiac remodelling and reduce atrial fibrillation risk [16]. Furthermore, RAAS blockers can be effective in primary prevention in patients with hypertension and left ventricular hypertrophy. In secondary prevention, RAAS inhibitors are often added to anti-arrhythmic drugs (i.e. amiodarone) to further decrease the odds for atrial fibrillation recurrence after cardioversion and in patients on medical therapy [17]. 
Table 1 Preferential indications, compelling and possible contraindications for angiotensin converting enzyme inhibitors (ACEIs) and angiotensin receptor blockers (ARBs) in the treatment of arterial hypertension (Modified from [4] with permission)

\begin{tabular}{lll}
\hline & ACEIs & ARBs \\
\hline Preferable conditions & LVH & LVH \\
& Microalbuminuria & Microalbuminuria \\
& Renal dysfunction & Renal dysfunction \\
& Previous stroke & Previous stroke \\
& Previous MI & Previous MI \\
& Heart failure & Heart failure \\
& Prevention of atrial fibrillation & Prevention of atrial fibrillation \\
& ESRD or proteinuria & ESRD or proteinuria \\
& Metabolic syndrome & Metabolic syndrome \\
& Diabetes mellitus & Diabetes mellitus \\
Compelling & Asymptomatic atherosclerosis & \\
contraindications & Peripheral artery disease & \\
& Pregnancy & Previous angioneurotic oedema \\
& Hyperkalaemia (potassium $>5.5$ mmol/L) & Pilateral renal stenosis \\
Possible & Bilateral renal stenosis & \\
\hline contraindications & Women with child-bearing potential without & Women with child-bearing potential without \\
& reliable contraception & reliable contraception \\
\hline
\end{tabular}

$L V H$ left ventricular hypertrophy, $M I$ myocardial infarction, ESRD end-stage renal disease

ACEIs or ARBs are beneficial also in normotensive patients at high risk and with atherosclerosis: their effect in reducing the composite primary outcome of CV death, nonfatal myocardial infarction or non-fatal stroke is independent of baseline SBP. This may support calls to base decisions about the prescription of these agents on the basis of each patient's estimated $\mathrm{CV}$ risk rather than just upon their BP level [18]. A consistent renoprotective effect of ACEIs and ARBs over other antihypertensive drugs, mainly calcium channel blockers, and placebo has been reported in type 2 diabetes, lowering the risk of serum creatinine doubling, macroalbuminuria and albuminuria $[19,20]$.

\section{ARE ANGIOTENSIN CONVERTING ENZYME INHIBITORS AND ANGIOTENSIN RECEPTOR BLOCKERS EQUALLY EFFECTIVE?}

Numerous data indicate that blockage of RAAS provides efficient BP control and favourable longterm outcomes in terms of CV events, mortality and improved quality of life (Table 2). However, in view of a more personalized approach to hypertensive patients based on specific profile and therapeutic options for each patient, ACEIs and ARBs cannot always be considered interchangeable. Of course, the most reliable information to compare ACEIs and ARBs can be retrieved from 


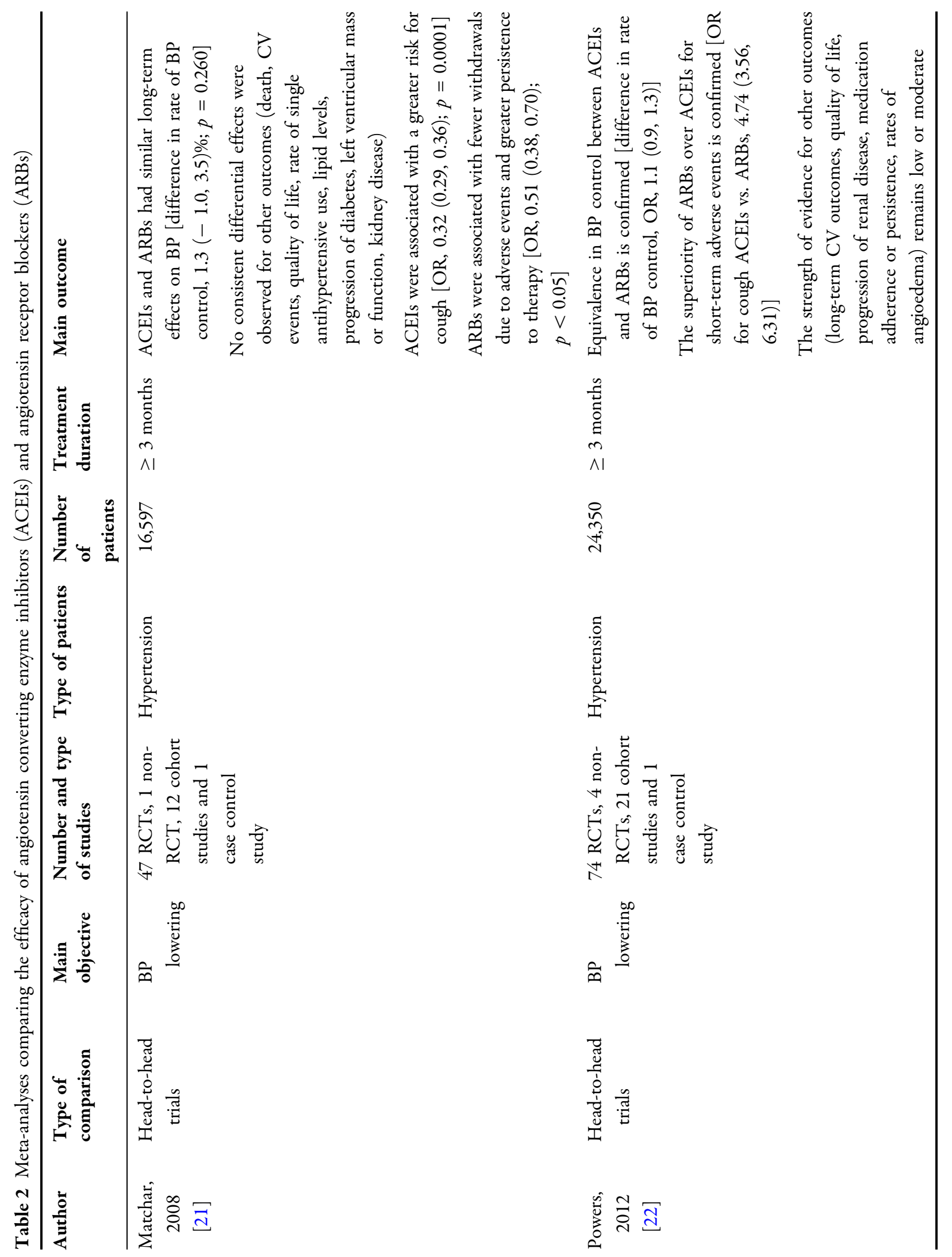




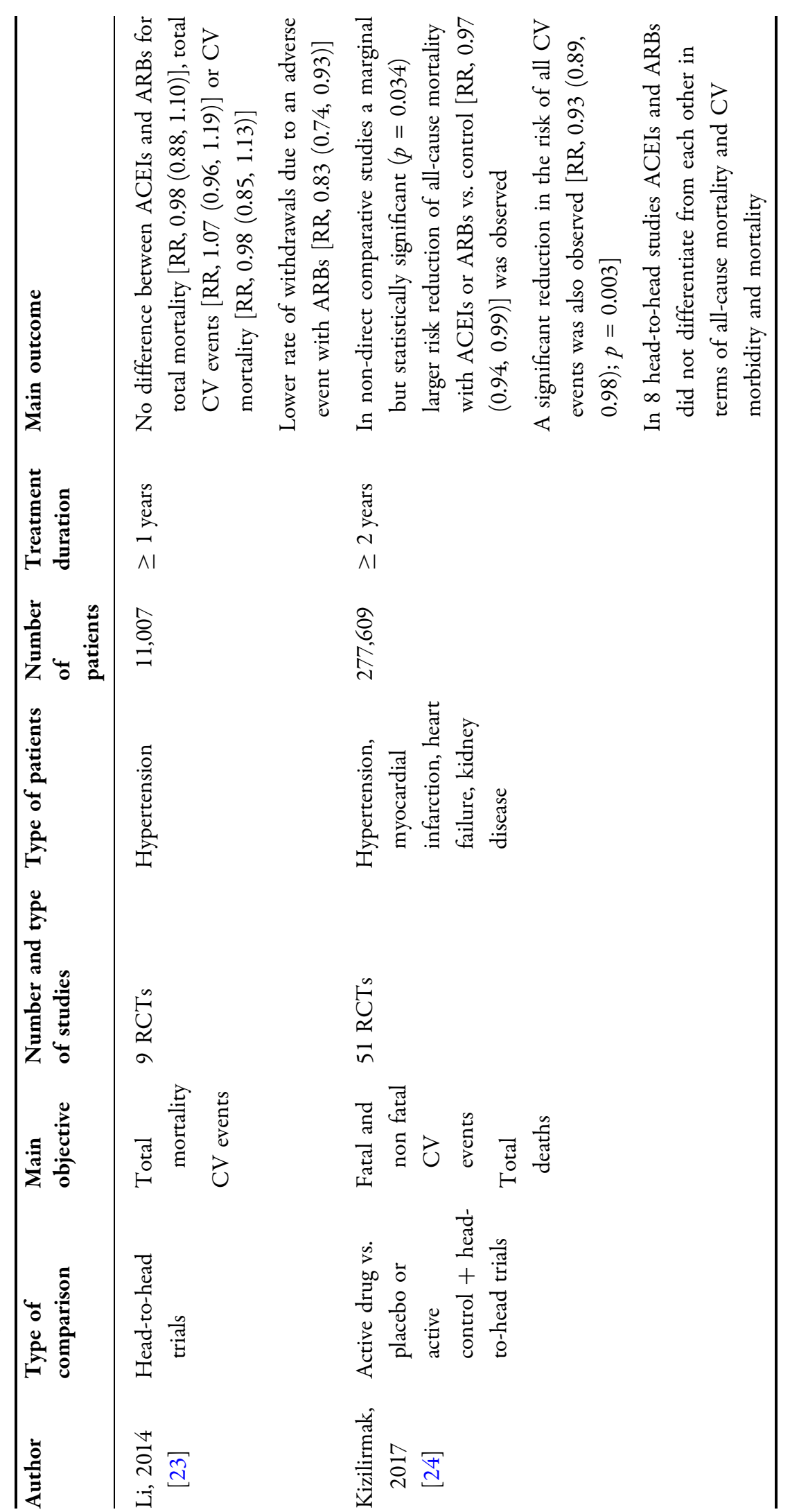




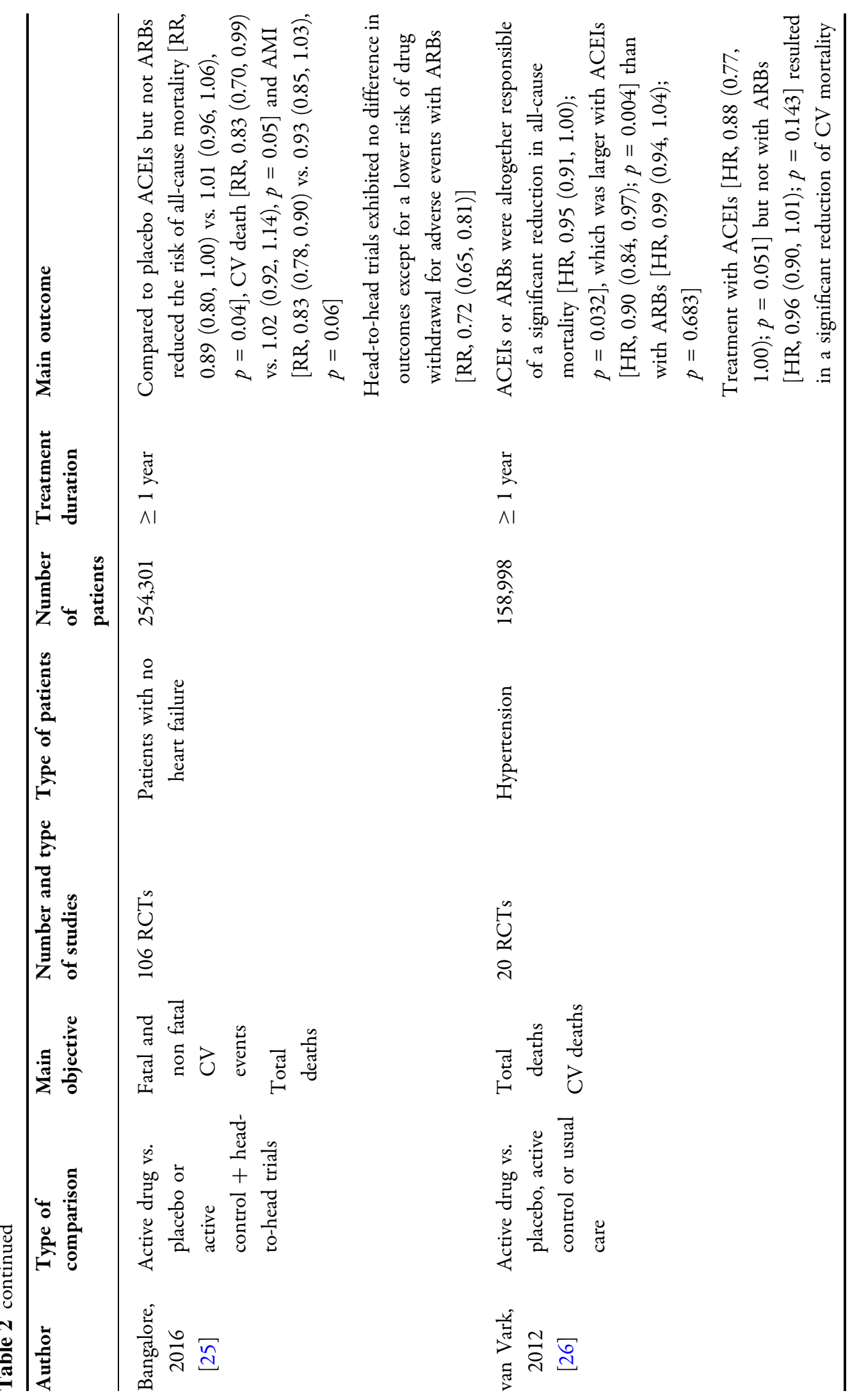




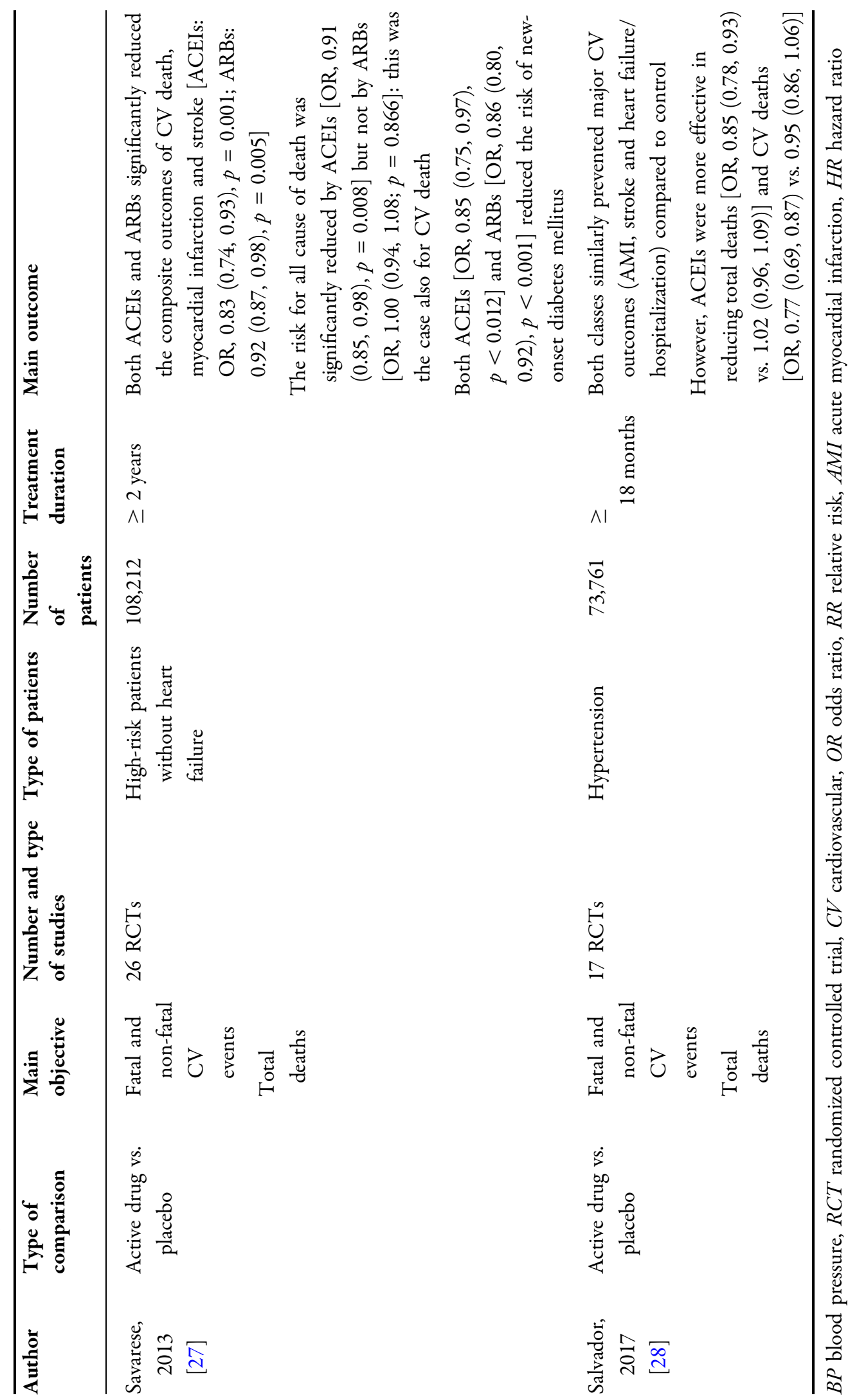


head-to-head clinical trials, since there is a "generation gap" between placebo-controlled trials performed on ACEIs and ARBs that does not allow indirect comparisons of these agents [29]. Headto-head studies have been important to test whether the observation that raised the hypothesis that ARBs may increase the risk of myocardial infarction (so-called myocardial infarction paradox) really holds true. Indeed, in a very large randomized controlled trial (ONTARGET, Ongoing Telmisartan Alone and in Combination with Ramipril Global Endpoint Trial) performed on about 30,000 patients, ACEIs and ARBs did not show any significant difference in myocardial infarction or any of the CV efficacy outcomes [30]. In addition to this, several meta-analyses have provided evidence that ARBs are as protective as ACEIs [31-33]. In a real-world practice study, however, ARBs reduced by $10 \%$ the incidence of $\mathrm{CV}$ mortality, non-fatal myocardial infarction, non-fatal stroke or hospitalization for CV disease at 4 years, providing superior protection against CV events than ACEIs in high-risk patients [34]. Furthermore, ARBs were better tolerated than ACEIs and showed a lower risk of drug withdrawal because of serious adverse effects [23, 25]. This favourable profile of ARBs in terms of lower incidence of serious adverse events should be considered in treating more challenging patients with concomitant disease, such as end-stage renal disease (ESRD) and diabetes-related retinopathy. Both ESRD and diabetic retinopathy can benefit from RAAS blockade that improves hypertension and hemodynamic alterations in microcirculation. In patients with ESRD, ARBs significantly $(p<0.05)$ reduced its incidence and doubling of serum creatinine concentration without, however, affecting total mortality [35]. A cost-effectiveness analysis indicated that the number needed to treat to prevent one patient from developing ESRD was 21 (95\% confidence interval, 12.94-56.82) with ARBs and $333(p=0.610)$ with ACEIs [35]. In patients with diabetes, RAAS blockade reduces the risk of diabetic retinopathy and increases the possibility of retinopathy regression. ACEIs might be better than ARBs for treating diabetic retinopathy and might exert the most beneficial effect on diabetic retinopathy of all widely used antihypertensive drug classes [36].
In summary, although both ACEIs and ARBs are equally important in the treatment of hypertension, there are substantial differences in their CV protective effects and likelihood of adverse events occurrence, mainly due to non-overlapping mechanisms of action [37].

\section{HEAD-TO-HEAD COMPARATIVE STUDIES OF OLMESARTAN AND ANGIOTENSIN CONVERTING ENZYME AGENTS}

Among ARBs class, olmesartan medoxomil is one of the latest generation compounds introduced in clinical practice for treating hypertension. Head-to-head comparative trials suggest that the efficacy of olmesartan is superior to that of commonly prescribed ACEIs. As shown in Fig. 2, compared to the ACEI ramipril, olmesartan affords significantly superior office SBP and DBP reductions in different categories of hypertensive patients, with a particularly more favourable action in patients aged 80 years or older, in men and in patients with metabolic syndrome [38]. As a monotherapy, olmesartan is also superior to ramipril in patients previously treated with two or more antihypertensive drugs or with an ACEI.

Olmesartan is more effective than ramipril in controlling BP over $24 \mathrm{~h}$, and particularly in the last $6 \mathrm{~h}$ from the drug intake and during awakening (morning surge) where the risk of $\mathrm{CV}$ events is higher (Fig. 3) [39]. It is also superior in sustained hypertensive patients, who present the concomitant occurrence of elevated office (SBP $\geq 140 \mathrm{mmHg}$ and/or $\mathrm{DBP} \geq 90 \mathrm{mmHg}$ ) and ambulatory BP (24-h SBP $\geq 130 \mathrm{mmHg}$ and/or DBP $\geq 80 \mathrm{mmHg}$ ) (Fig. 3) [39]. Olmesartan is also capable of efficiently controlling BP when the cut-off for normalization is lower than 150/90 $\mathrm{mmHg}$ and the chance of attaining BP normalization is significantly larger under olmesartan than under ramipril for both the thresholds considered (140/90 mmHg: $54.4 \%$ vs $46.7 \%, \quad p=0.012 ; \quad 150 / 90 \mathrm{mmHg}: \quad 68.4 \%$ vs $60.3 \%, p=0.006)[40]$. 

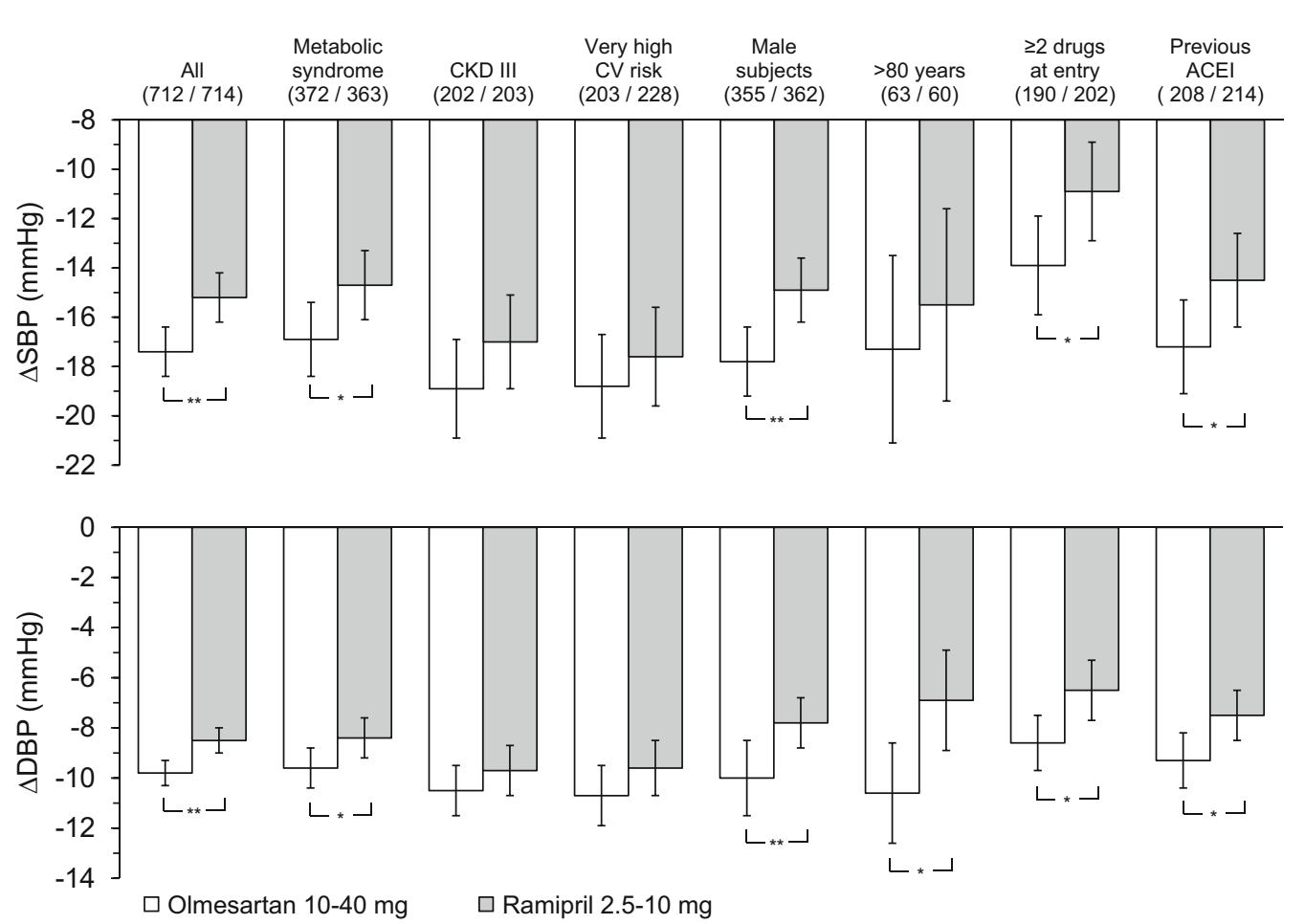

Fig. 2 Baseline-adjusted office systolic blood pressure (SBP) and diastolic blood pressure (DBP) mean changes (and 95\% confidence intervals) from baseline after 12 weeks of double-blind treatment with olmesartan medoxomil $10-40 \mathrm{mg}$ (open bars) or ramipril $2.5-10 \mathrm{mg}$ (grey bars) in the whole study population $(n=1426)$ and in high-risk subgroups. The numbers in parentheses indicate the number of subjects treated with olmesartan and ramipril, respectively. The statistical significance of

In studies using combinations based on these agents, olmesartan with amlodipine was superior to perindopril with amlodipine in reducing both central SBP and 24-h DBP (Fig. 4), and normalized BP in $75.6 \%$ of patients (mean seated $\mathrm{BP}<140 / 90 \mathrm{mmHg}$ ) compared with $57.5 \%$ of perindopril recipients $(p<0.0001)$ [41]. A post hoc analysis of the SEVITENSION (efficacy of SEVIkar compared to the combination of perindopril plus amlodipine on central arterial BP in patients with hyperTENSION) study confirmed greater efficacy of olmesartan plus amlodipine compared to the combination of perindopril with amlodipine between-treatment differences is indicated by asterisks $\left({ }^{* * *} p<0.001,{ }^{* *} p<0.01\right)$. Reprinted by permission from Springer Nature Customer Service Centre GmbH: Springer, High Blood Pressure \& Cardiovascular Prevention, Olmesartan vs. Ramipril in Elderly Hypertensive Patients: Review of Data from Two Published Randomized, Double-Blind Studies, Stefano Omboni, Ettore Malacco, Jean-Michel Mallion et al, 2014

in diabetic patients; after 24 weeks, a significantly higher proportion of patients treated with the combination including olmesartan had normalized BP $(<130 / 80 \mathrm{mmHg}$ according to the study protocol: $37.6 \%$ vs $21.8 \%$; $p=0.018 ; \quad$ BP < 140/90 mmHg: $\quad 73.3 \% \quad$ vs $59.1 \% ; p=0.030)$ [42].

Olmesartan with amlodipine was non-inferior to perindopril and amlodipine in reducing central SBP and office DBP after 24 weeks of treatment and at $48 \mathrm{~h}$ from the last administration in diabetic patients. The percentage of responders and percentage of those with normalized BP were similar between the two groups 


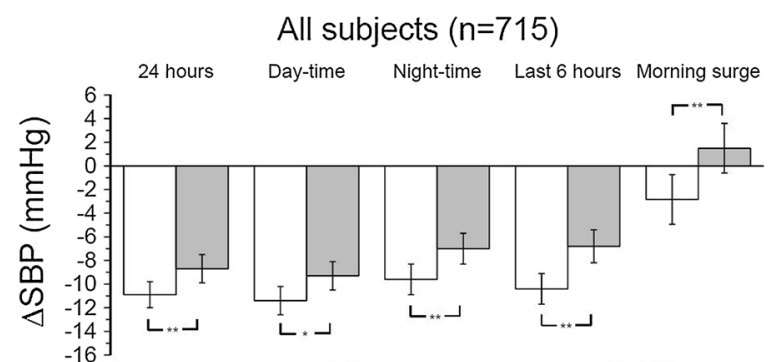

Sustained hypertensives $(n=582)$

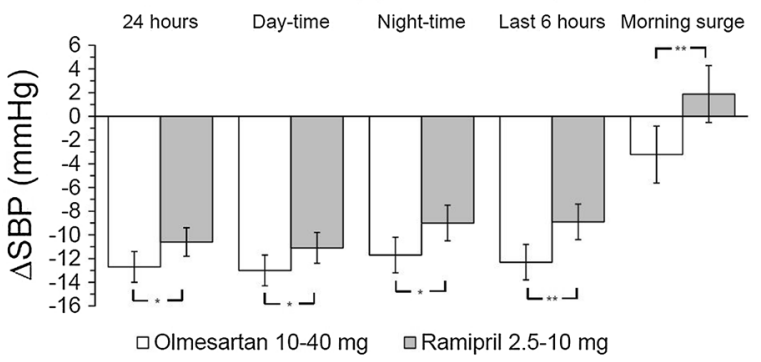

Fig. 3 Baseline-adjusted 24-h, daytime, night-time, last 6-h and morning surge SBP mean changes (and 95\% confidence interval) after 12 weeks of double-blind treatment with olmesartan 10-40 mg (open bars) and ramipril 2.5-10 mg (grey bars). Data are shown for the whole population $(n=715)$ and for sustained hypertensive patients $(n=582)$. Asterisks refer to the statistical significance of between-treatment differences $\left({ }^{* *} p<0.001 ;{ }^{*} p<0.05\right)$. Redrawn from Omboni $S$, Malacco E, Mallion JM, Volpe M, Zanchetti A, Study Group. Twenty-four hour and early morning blood pressure control of olmesartan vs. ramipril in elderly hypertensive patients: pooled individual data analysis of two randomized, double-blind, parallel-group studies. J Hypertens. 2012;30(7):1468-77. https://journals.lww. com/jhypertension/Abstract/2012/07000/Twenty_four_ hour_and_early_morning_blood_pressure.28.aspx

$[43,44]$. However, the olmesartan plus amlodipine combination provided longer-lasting efficacy in terms of office BP reduction compared to the perindopril plus amlodipine combination [43]. Both combinations were well tolerated and showed a good safety profile $[43,44]$. Peripheral BP, augmentation index and pulse wave velocity were significantly lower in both groups after 24 weeks of treatment and $48 \mathrm{~h}$ after the missed dose, observing a trend to a greater reduction in parameters related to the central aortic BP in the olmesartan plus amlodipine group [44].

\section{SAFETY OF ANGIOTENSIN RECEPTOR BLOCKERS AND ANGIOTENSIN CONVERTING ENZYME INHIBITORS}

Despite similar antihypertensive properties and a favourable safety profile for both ACEIs and ARBs, evidence indicates that patients treated with ARBs have lower rates of withdrawal for adverse events and greater persistence to therapy than those treated with ACEIs. This point is pivotal in the choice of long-term therapies in current medical practice. Indeed, even if caused by adverse events of minor health impact, permanent discontinuations of treatment have obvious untoward implications on health by depriving the hypertensive patients of the beneficial effects of BP lowering. When compared with placebo treatment, all major classes of BPlowering drugs (diuretics, beta-blockers, calcium channel blockers, ACEIs and central agents) significantly and markedly (twofold to threefold) increase treatment discontinuations, with the relevant exception of ARBs that have been found not to increase discontinuations over those occurring with placebo (Fig. 5) [45]. Cough is a well-described class adverse effect of ACEIs, with an incidence ranging between 5\% and $35 \%$ and it often causes treatment discontinuation [46]. The incidence of ARB-induced cough is much lower $(3.2 \%$ in controlled trials and $0.6 \%$ in cohort studies). Although cough may occur with ARBs, they are considered an alternative treatment for patients who discontinued ACEI because of cough and who need the blockade of the renin-angiotensin cascade [46]. The mechanism of action of ARBs that does not affect the metabolism of bradykinin contributes to limit the rate of angioedema $(0.11 \%)$ compared to that observed with ACEIs $(0.3 \%)$ in controlled trials [47]. Switching ACEIs to ARBs in patients with previous ACEIs angioedema is quite safe, but close monitoring of those patients is mandatory [47].

Since ARBs act on the renin-angiotensin system to produce angiotensin II that is not only an effective antihypertensive agent but also regulates cell growth, their potential for an increased risk of cancer has been widely 


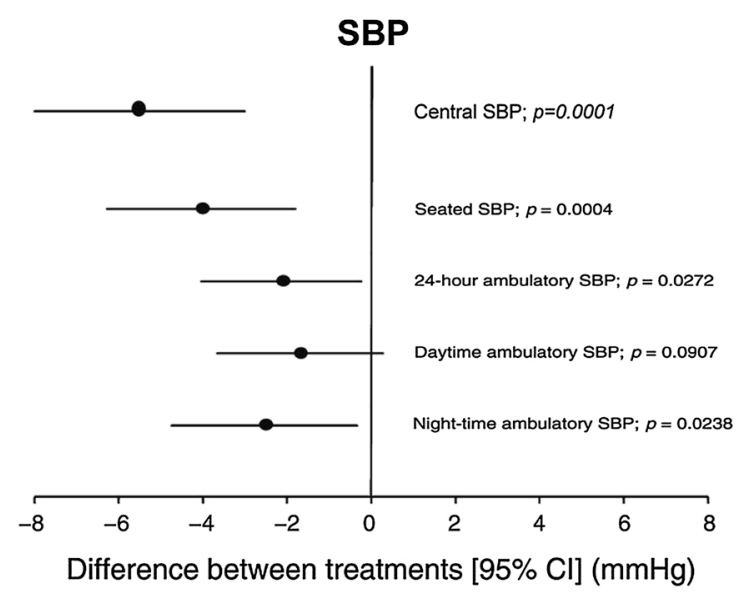

Favors OLM/AML $40 / 10 \mathrm{mg}$

Favors PER/AML $8 / 10 \mathrm{mg}$

Fig. 4 Forest plot of the mean differences (and 95\% confidence intervals) between patients treated with the olmesartan $40 \mathrm{mg}$ plus amlodipine $10 \mathrm{mg}$ (OLM/AML, $n=221)$ and the perindopril $8 \mathrm{mg}$ plus amlodipine $10 \mathrm{mg}$ (PER/AML, $n=221$ ) combination in the absolute change from baseline to the final examination in systolic blood pressure (SBP) and diastolic blood pressure (DBP). $p$ values represent the superiority comparison between the two

investigated. In 2010, a meta-analysis by Sipahi and coworkers [48] reported that ARBs were associated with a modestly increased risk of new cancer occurrence without, however, resulting in a significant excess in cancer deaths. Since oncogenesis, tumour growth and treatment failure followed by death are typically slow processes, it is not possible to conclude regarding the effect of ARBs on cancer-related deaths with short-term clinical trials [48]. This has been discussed in an expert consensus paper analysing the available literature [49]. In addition, other studies did not show any significant association between the use of ACEIs or ARBs and the overall risk of cancer [50]. Therefore, it may be plausible to exclude any correlation between ARBs and cancer. Overall, treatment with both ACEIs and ARBs reduces the occurrence of atrial fibrillation, diabetes onset and the likelihood of bone fractures (Table 3).

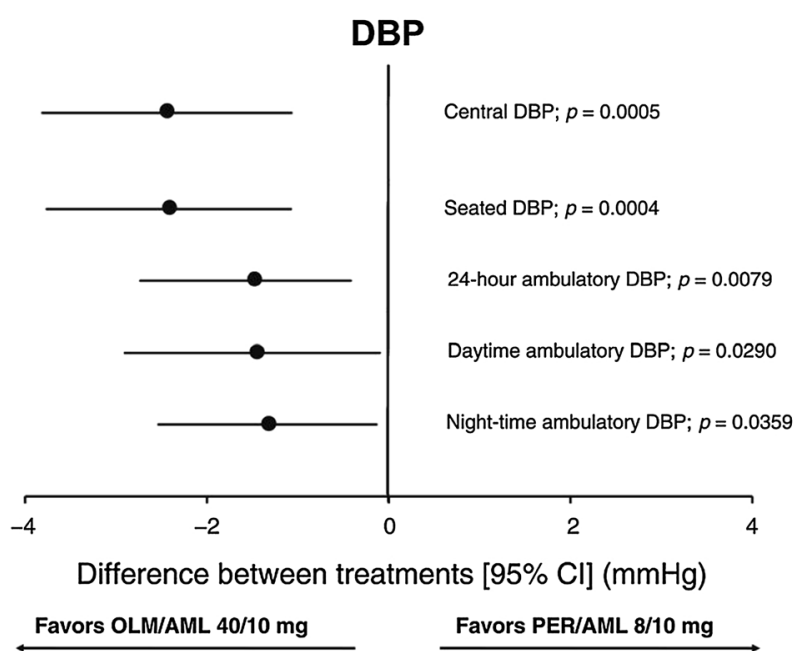

treatment groups. Reprinted by permission from Springer Nature Customer Service Centre GmbH: Springer, Advances in Therapy, (The Fixed-Dose Combination of Olmesartan/Amlodipine Was Superior in Central Aortic Blood Pressure Reduction Compared with Perindopril/ Amlodipine: A Randomized, Double-Blind Trial in Patients with Hypertension, Luis Ruilope; Angie Schaefer, 2013

Olmesartan shows similar tolerability in terms of incidence of adverse events as other ARBs (losartan, valsartan, candesartan and irbesartan), with similar relative risk of dizziness, headache and diarrhoea as losartan or valsartan [54]. In 2012, a case series of sprue-like syndrome was reported regarding the use of olmesartan [55]. However, patients treated with other ARBs presented similar clinical-pathological findings as those described in the limited reports of olmesartan-associated enteropathy, thus suggesting the presence of a class effect, rather than an olmesartan-specific adverse event [56-59]. In elderly patients, olmesartan showed a similar rate of adverse events compared to ramipril; the risk of adverse drug reaction was not related to BP levels achieved during treatment [38]. In combination with amlodipine, olmesartan showed a similar tolerability profile to perindopril, but lower rate of 


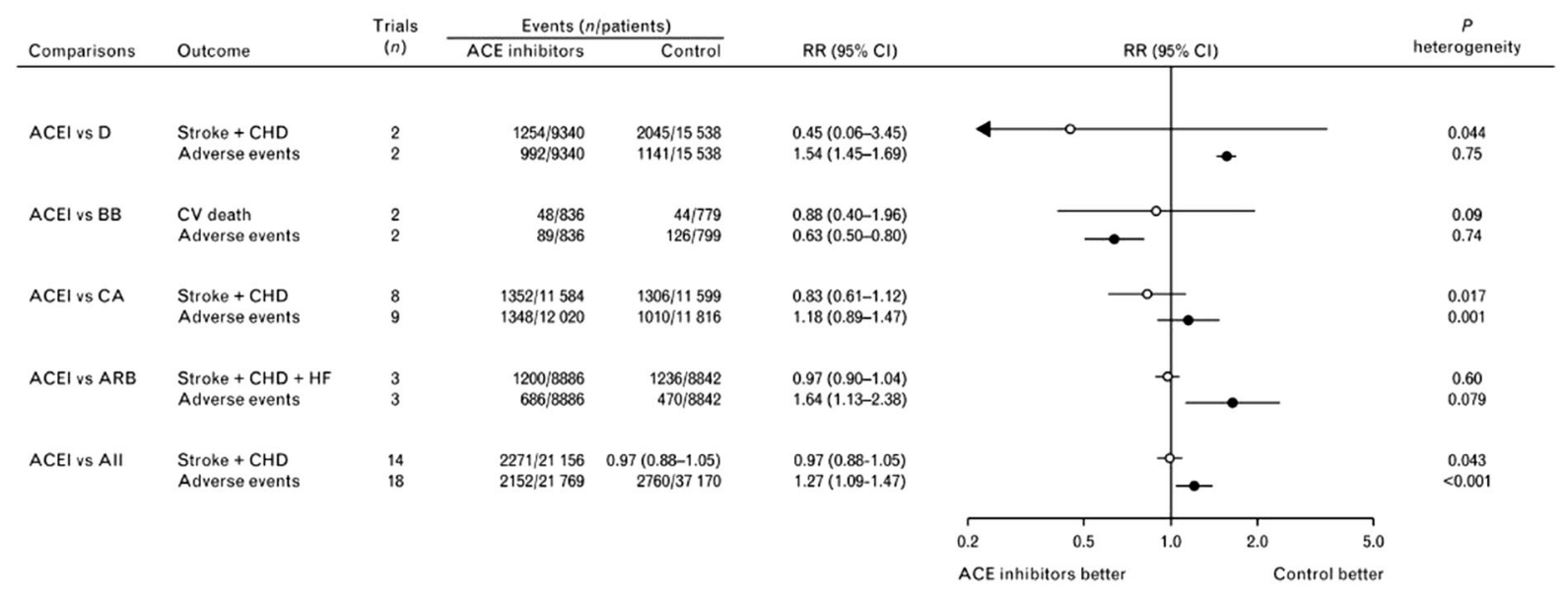

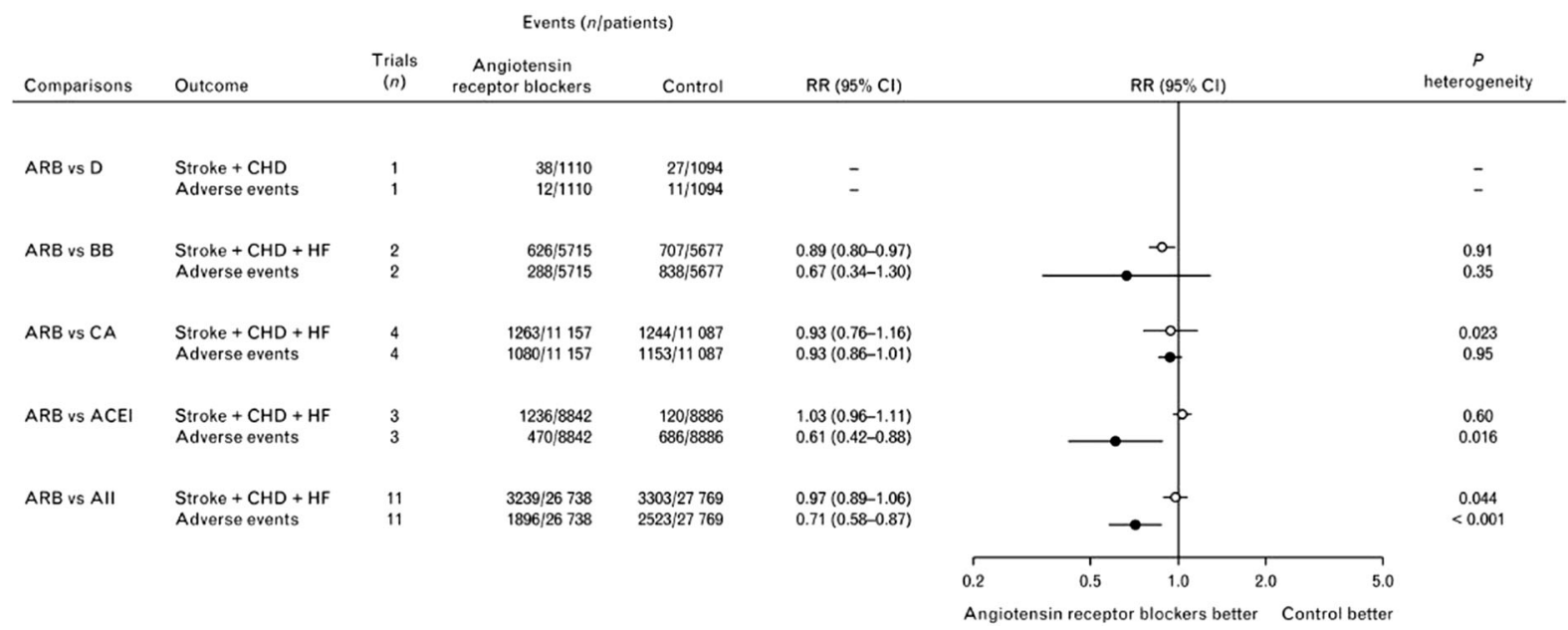

Fig. 5 Comparison of the effects of blood pressurelowering treatment based on angiotensin converting enzyme (ACE) inhibitors (a) or angiotensin receptor blockers (b) vs. the same blood pressure lowering based on other pharmacological classes on cardiovascular events and on treatment discontinuations for adverse events. The type of cardiovascular events considered was the composite of stroke and coronary heart disease or the composite of stroke, coronary heart disease and heart failure; or cardiovascular death, as indicated. ACEI angiotensin converting enzyme inhibitors, ARB angiotensin receptor

discontinuation due to treatment-related adverse events. The most common adverse events were peripheral oedema, nasopharyngitis and cough with lower incidence with olmesartan [41]. In patients with diabetes mellitus, blockers, BB beta-blockers, CA calcium antagonists, $\mathrm{CHD}$ coronary heart disease, CI confidence interval, $\mathrm{CV}$ cardiovascular, D diuretics, HF heart failure, RR risk ratio. Redrawn with permission from Thomopoulos C, Parati G, Zanchetti A. Effects of blood-pressure-lowering treatment in hypertension: 9. Discontinuations for adverse events attributed to different classes of antihypertensive drugs: meta-analyses of randomized trials. J Hypertens. 2016;34(10):1921-32. https://journals.lww.com/jhyper tension/pages/default.aspx

24 weeks of treatment with amlodipine combined with either olmesartan or perindopril showed that only few patients in both groups discontinued because of an adverse effect with any relationship to study drug [43] (Table 4). 


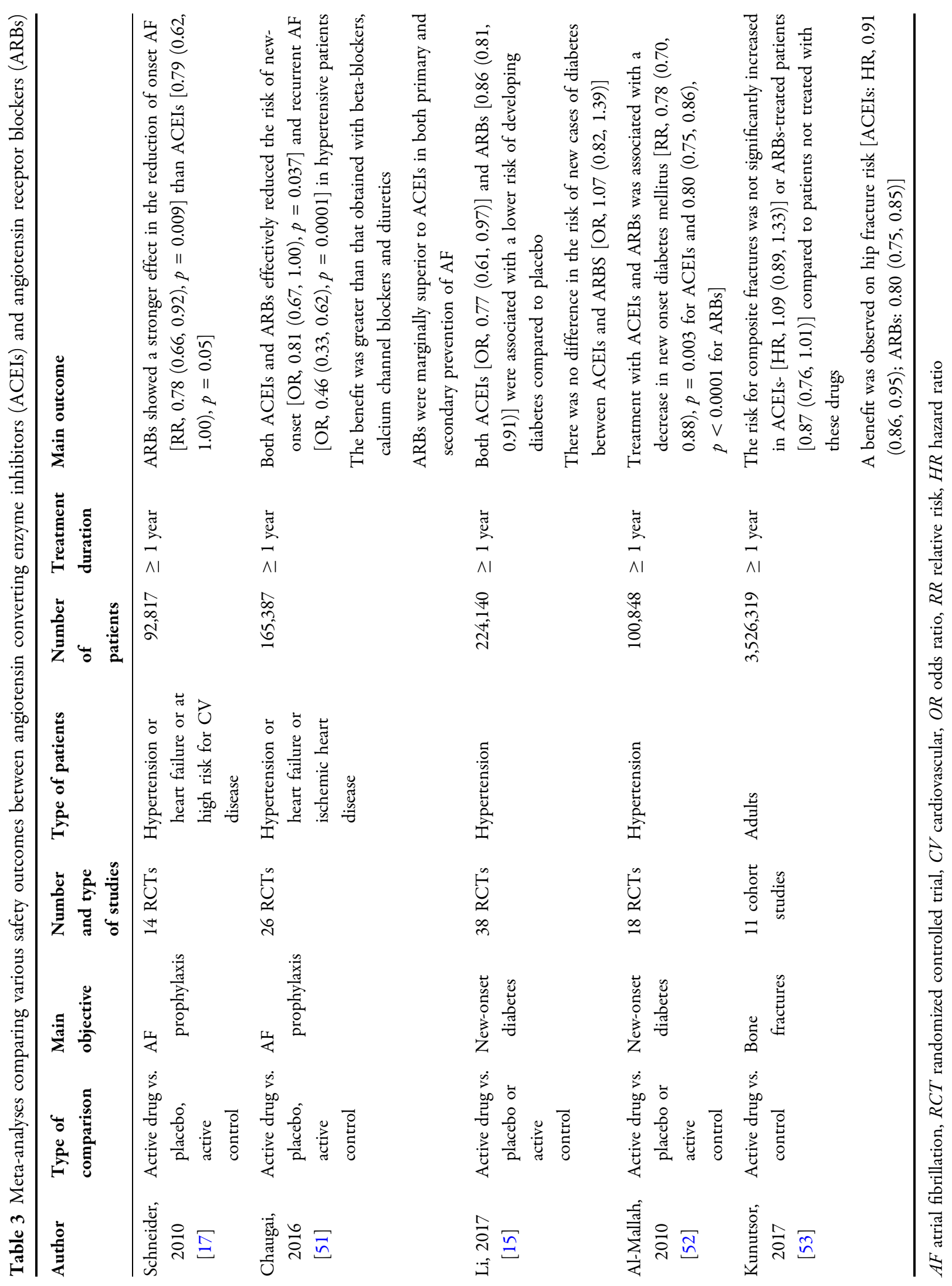




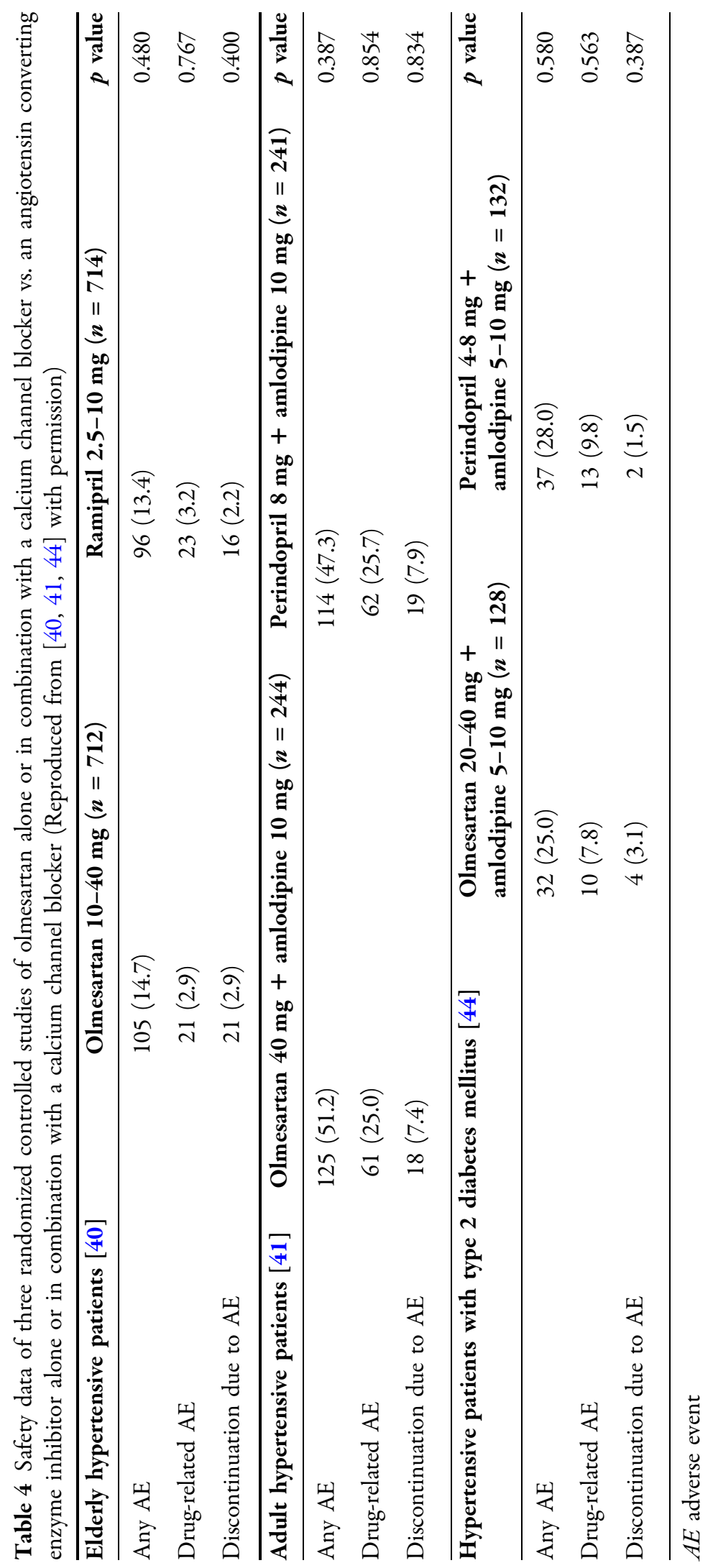




\section{CONCLUSIONS}

RAAS blockade is an effective strategy to obtain BP control and prevent CVDs. Both ACEIs and ARBs are characterized by similar antihypertensive activity; however, ARBs afford lower incidence of adverse reactions and allow greater adherence to treatment. Among ARBs, the recent introduction of olmesartan in clinical practice offers a significant therapeutic opportunity, as monotherapy or in combination, for specific categories of patients, including elderly people, diabetics and patients with metabolic syndrome. In these patients, the higher BP stability in the whole 24 -h period achieved with olmesartan may provide an important contribution to prevent effect against stroke and $\mathrm{CV}$ events.

\section{ACKNOWLEDGEMENTS}

Funding. Article preparation and Open Access fee were funded by Menarini International Operations Luxembourg S.A. (M.I.O.L.). No article processing charges were received by the journal for the publication of this article. All authors had full access to all of the data in this study and take complete responsibility for the integrity of the data and accuracy of the data analysis.

Authorship. All named authors meet the International Committee of Medical Journal Editors (ICMJE) criteria for authorship for this article, take responsibility for the integrity of the work as a whole, and have given their approval for this version to be published.

Authorship Contributions. Stefano Omboni and Massimo Volpe conceived the idea behind the review. Stefano Omboni wrote the manuscript. Massimo Volpe critically revised the manuscript.

Disclosures. Stefano Omboni received a grant for the preparation of the manuscript from Menarini International Operations Luxembourg S.A. (M.I.O.L.). Massimo Volpe received a grant for the preparation of the manuscript from Menarini International Operations Luxembourg S.A. (M.I.O.L.).

Compliance with Ethics Guidelines. This article is based on previously conducted studies and does not contain any studies with human participants or animals performed by any of the authors.

Data Availability. Data sharing is not applicable to this article as no datasets were generated or analyzed for the preparation of this review.

Open Access. This article is distributed under the terms of the Creative Commons Attribution-NonCommercial 4.0 International License (http://creativecommons.org/licenses/ by-nc/4.0/), which permits any noncommercial use, distribution, and reproduction in any medium, provided you give appropriate credit to the original author(s) and the source, provide a link to the Creative Commons license, and indicate if changes were made.

\section{REFERENCES}

1. GBD 2015 Mortality and Causes of Death Collaborators. Global, regional, and national life expectancy, all-cause mortality, and cause-specific mortality for 249 causes of death, 1980-2015: a systematic analysis for the Global Burden of Disease Study 2015. Lancet. 2016;388:1459-1544.

2. Global Burden of Metabolic Risk Factors for Chronic Diseases Collaboration. Cardiovascular disease, chronic kidney disease, and diabetes mortality burden of cardiometabolic risk factors from 1980 to 2010: a comparative risk assessment. Lancet Diabetes Endocrinol. 2014;2014(2):634-47.

3. Rapsomaniki E, Timmis A, George J, et al. Blood pressure and incidence of twelve cardiovascular diseases: lifetime risks, healthy life-years lost, and age-specific associations in 1.25 million people. Lancet. 2014;383:1899-911.

4. Williams B, Mancia G, Spiering W, et al.. 2018 ESC/ ESH Guidelines for the management of arterial hypertension. Eur Heart J. 2018;39:3021-104.

5. Ettehad D, Emdin CA, Kiran A, et al. Blood pressure lowering for prevention of cardiovascular disease 
and death: a systematic review and meta-analysis. Lancet. 2016;387:957-67.

6. Katsanos AH, Filippatou A, Manios E, et al. Blood pressure reduction and secondary stroke prevention: a systematic review and metaregression analysis of randomized clinical trials. Hypertension. 2017;69:171-9.

7. Zanchetti A, Thomopoulos C, Parati G. Randomized controlled trials of blood pressure lowering in hypertension: a critical reappraisal. Circ Res. 2015;116:1058-73.

8. Thomopoulos C, Parati G, Zanchetti A. Effects of blood pressure lowering on outcome incidence in hypertension: 3. Effects in patients at different levels of cardiovascular risk-overview and metaanalyses of randomized trials. J Hypertens. 2014;32:2305-14.

9. Thomopoulos C, Parati G, Zanchetti A. Effects of blood-pressure-lowering treatment on outcome incidence in hypertension: 10-should blood pressure management differ in hypertensive patients with and without diabetes mellitus? Overview and meta-analyses of randomized trials. J Hypertens. 2017;35:922-44.

10. Thomopoulos C, Parati G, Zanchetti A. Effects of blood pressure lowering on outcome incidence in hypertension: 7. Effects of more vs. less intensive blood pressure lowering and different achieved blood pressure levels-updated overview and meta-analyses of randomized trials. J Hypertens. 2016;34:613-22.

11. Thomopoulos C, Parati G, Zanchetti A. Effects of blood-pressure-lowering treatment on outcome incidence. 12. Effects in individuals with highnormal and normal blood pressure: overview and meta-analyses of randomized trials. J Hypertens. 2017;35:2150-60.

12. Whelton PK, Carey RM, Aronow WS, et al. 2017 ACC/AHA/AAPA/ABC/ACPM/AGS/APhA/ASH/ ASPC/NMA/PCNA guideline for the prevention, detection, evaluation, and management of high blood pressure in adults: a report of the American College of Cardiology/American Heart Association Task Force on Clinical Practice Guidelines. Hypertension. 2018;71:e13-115.

13. Kronish IM, Woodward M, Sergie Z, Ogedegbe G, Falzon L, Mann DM. Meta-analysis: impact of drug class on adherence to antihypertensives. Circulation. 2011;123:1611-21.

14. Brownstein DJ, Salagre E, Köhler C, et al. Blockade of the angiotensin system improves mental health domain of quality of life: a meta-analysis of randomized clinical trials. Aust N Z J Psychiatry. 2018;52:24-38.
15. Li Z, Li Y, Liu Y, Xu W, Wang Q. Comparative risk of new-onset diabetes mellitus for antihypertensive drugs: a network meta-analysis. J Clin Hypertens (Greenwich). 2017;19:1348-56.

16. Zhao D, Wang ZM, Wang LS. Prevention of atrial fibrillation with renin-angiotensin system inhibitors on essential hypertensive patients: a metaanalysis of randomized controlled trials. J Biomed Res. 2015;29:475-85.

17. Schneider MP, Hua TA, Böhm M, Wachtell K, Kjeldsen SE, Schmieder RE. Prevention of atrial fibrillation by renin-angiotensin system inhibition a meta-analysis. J Am Coll Cardiol. 2010;55:2299-307.

18. McAlister FA, Renin Angiotension System Modulator Meta-Analysis Investigators. Angiotensin-converting enzyme inhibitors or angiotensin receptor blockers are beneficial in normotensive atherosclerotic patients: a collaborative meta-analysis of randomized trials. Eur Heart J. 2012;33:505-14.

19. Vejakama P, Thakkinstian A, Lertrattananon D, Ingsathit A, Ngarmukos C, Attia J. Reno-protective effects of renin-angiotensin system blockade in type 2 diabetic patients: a systematic review and network meta-analysis. Diabetologia. 2012;55:56678.

20. Wu HY, Huang JW, Lin HJ, et al. Comparative effectiveness of renin-angiotensin system blockers and other antihypertensive drugs in patients with diabetes: systematic review and bayesian network meta-analysis. BMJ. 2013;347:f6008.

21. Matchar DB, McCrory DC, Orlando LA, et al. Systematic review: comparative effectiveness of angiotensin-converting enzyme inhibitors and angiotensin II receptor blockers for treating essential hypertension. Ann Intern Med. 2008;148:16-29.

22. Powers BJ, Coeytaux RR, Dolor RJ, et al. Updated report on comparative effectiveness of ACE inhibitors, ARBs, and direct renin inhibitors for patients with essential hypertension: much more data, little new information. J Gen Intern Med. 2012;27:716-29.

23. Li EC, Heran BS, Wright JM. Angiotensin converting enzyme (ACE) inhibitors versus angiotensin receptor blockers for primary hypertension. Cochrane Database Syst Rev. 2014;(8):CD009096.

24. Kızılırmak P, Üresin Y, Özdemir O, Kılıçkıran Avcı B, Tokgözoğlu L, Öngen Z. Renin-angiotensin-aldosterone system blockers and cardiovascular outcomes: a meta-analysis of randomized clinical trials. Turk Kardiyol Dern Ars. 2017;45:49-66. 
25. Bangalore S, Fakheri R, Toklu B, Ogedegbe G, Weintraub H, Messerli FH. Angiotensin-converting enzyme inhibitors or angiotensin receptor blockers in patients without heart failure? Insights from 254,301 patients from randomized trials. Mayo Clin Proc. 2016;91:51-60.

26. van Vark LC, Bertrand M, Akkerhuis KM, et al. Angiotensin-converting enzyme inhibitors reduce mortality in hypertension: a meta-analysis of randomized clinical trials of renin-angiotensin-aldosterone system inhibitors involving 158,998 patients. Eur Heart J. 2012;33:2088-97.

27. Savarese G, Costanzo P, Cleland JG, et al. A metaanalysis reporting effects of angiotensin-converting enzyme inhibitors and angiotensin receptor blockers in patients without heart failure. J Am Coll Cardiol. 2013;61:131-42.

28. Salvador GL, Marmentini VM, Cosmo WR, Junior EL. Angiotensin-converting enzyme inhibitors reduce mortality compared to angiotensin receptor blockers: systematic review and meta-analysis. Eur J Prev Cardiol. 2017;24:1914-24.

29. Messerli FH, Bangalore S. Angiotensin receptor blockers reduce cardiovascular events, including the risk of myocardial infarction. Circulation. 2017;135:2085-7.

30. ONTARGET Investigators, Yusuf S, Teo KK, et al. Telmisartan, ramipril, or both in patients at high risk for vascular events. $\mathrm{N}$ Engl J Med. 2008;358:1547-59.

31. de la Sierra A, Volpe M. Olmesartan-based therapies: an effective way to improve blood pressure control and cardiovascular protection. J Hypertens. 2013;31(Suppl. 1):S13-7.

32. Volpe M, Tocci G, Sciarretta S, Verdecchia P, Trimarco B, Mancia G. Angiotensin II receptor blockers and myocardial infarction: an updated analysis of randomized clinical trials. J Hypertens. 2009;27:941-6.

33. Bangalore S, Kumar S, Wetterslev J, Messerli FH. Angiotensin receptor blockers and risk of myocardial infarction: meta-analyses and trial sequential analyses of 147020 patients from randomised trials. BMJ. 2011;342:d2234.

34. Potier L, Roussel R, Elbez Y, et al. Angiotensinconverting enzyme inhibitors and angiotensin receptor blockers in high vascular risk. Heart. 2017;103:1339-46.

35. Stafylas PC, Sarafidis PA, Grekas DM, Lasaridis AN. A cost-effectiveness analysis of angiotensin-converting enzyme inhibitors and angiotensin receptor blockers in diabetic nephropathy. J Clin Hypertens (Greenwich). 2007;9:751-9.

36. Wang B, Wang F, Zhang Y, et al. Effects of RAS inhibitors on diabetic retinopathy: a systematic review and meta-analysis. Lancet Diabetes Endocrinol. 2015;3:263-74.

37. Dézsi CA. Differences in the clinical effects of angiotensin-converting enzyme inhibitors and Angiotensin receptor blockers: a critical review of the evidence. Am J Cardiovasc Drugs. 2014;14:167-73.

38. Omboni S, Malacco E, Mallion JM, Fabrizzi P, Volpe M. Olmesartan vs. ramipril in elderly hypertensive patients: review of data from two published randomized, double-blind studies. High Blood Press Cardiovasc Prev. 2014;21:1-19.

39. Omboni S, Malacco E, Mallion JM, Volpe M, Zanchetti A, Study Group. Twenty-four hour and early morning blood pressure control of olmesartan vs. ramipril in elderly hypertensive patients: pooled individual data analysis of two randomized, doubleblind, parallel-group studies. J Hypertens. 2012;30:1468-77.

40. Omboni S, Malacco E, Mallion JM, Volpe M. Olmesartan vs ramipril in the treatment of hypertension and associated clinical conditions in the elderly: a reanalysis of two large double-blind, randomized studies at the light of the most recent blood pressure targets recommended by guidelines. Clin Interv Aging. 2015;10:1575-86.

41. Ruilope L, Schaefer A. The fixed-dose combination of olmesartan/amlodipine was superior in central aortic blood pressure reduction compared with perindopril/amlodipine: a randomized, doubleblind trial in patients with hypertension. Adv Ther. 2013;30:1086-99.

42. Ruilope LM, SEVITENSION Study Investigators. Fixed-combination olmesartan/amlodipine was superior to perindopril + amlodipine in reducing central systolic blood pressure in hypertensive patients with diabetes. J Clin Hypertens (Greenwich). 2016;18:528-35.

43. Redon J, Pichler G, Missed Dose Study Group. Comparative study of the efficacy of olmesartan/ amlodipine vs. perindopril/amlodipine in peripheral and central blood pressure parameters after missed dose in type 2 diabetes. Am J Hypertens. 2016;29:1055-62.

44. Redon J, Pichler G, Missed Dose Study Group. Comparative study of the efficacy of olmesartan/ amlodipine vs. perindopril/amlodipine in peripheral blood pressure after missed dose in type 2 diabetes. J Hypertens. 2016;34:359-67. 
45. Thomopoulos C, Parati G, Zanchetti A. Effects of blood-pressure-lowering treatment in hypertension: 9. Discontinuations for adverse events attributed to different classes of antihypertensive drugs: meta-analyses of randomized trials. J Hypertens. 2016;34:1921-32.

46. Omboni S, Borghi C. Zofenopril and incidence of cough: a review of published and unpublished data. Ther Clin Risk Manag. 2011;7:459-71.

47. Bezalel S, Mahlab-Guri K, Asher I, Werner B, Sthoeger ZM. Angiotensin-converting enzyme inhibitor-induced angioedema. Am J Med. 2015;128:120-5.

48. Sipahi I, Debanne SM, Rowland DY, Simon DI, Fang JC. Angiotensin-receptor blockade and risk of cancer: meta-analysis of randomised controlled trials. Lancet Oncol. 2010;11:627-36.

49. Volpe M, Azizi M, Danser AH, Nguyen G, Ruilope LM. Twisting arms to angiotensin receptor blockers/antagonists: the turn of cancer. Eur Heart J. 2011;32:19-22.

50. Yoon C, Yang HS, Jeon I, Chang Y, Park SM. Use of angiotensin-converting-enzyme inhibitors or angiotensin-receptor blockers and cancer risk: a meta-analysis of observational studies. CMAJ. 2011;183:E1073-84.

51. Chaugai S, Meng WY, Ali Sepehry A. Effects of RAAS blockers on atrial fibrillation prophylaxis: an updated systematic review and meta-analysis of randomized controlled trials. J Cardiovasc Pharmacol Ther. 2016;21:388-404.

52. Al-Mallah M, Khawaja O, Sinno M, Alzohaili O, Samra AB. Do angiotensin converting enzyme inhibitors or angiotensin receptor blockers prevent diabetes mellitus? A meta-analysis. Cardiol J. 2010;17:448-56.

53. Kunutsor SK, Blom AW, Whitehouse MR, Kehoe PG, Laukkanen JA. Renin-angiotensin system inhibitors and risk of fractures: a prospective cohort study and meta-analysis of published observational cohort studies. Eur J Epidemiol. 2017;32:947-59.

54. Tsoi B, Akioyamen LE, Bonner A, et al. Comparative efficacy of angiotensin II antagonists in essential hypertension: systematic review and network metaanalysis of randomised controlled trials. Heart Lung Circ. 2017;27:666-82.

55. Burbure N, Lebwohl B, Arguelles-Grande C, Green $\mathrm{PH}$, Bhagat G, Lagana S. Olmesartan-associated spruelike enteropathy: a systematic review with emphasis on histopathology. Hum Pathol. 2016;50:127-34.

56. Zanelli M, Negro A, Santi R, et al. Letter: sprue-like enteropathy associated with angiotensin II receptor blockers other than olmesartan. Aliment Pharmacol Ther. 2017;46:471-3.

57. Choi EY, McKenna BJ. Olmesartan-associated enteropathy: a review of clinical and histologic findings. Arch Pathol Lab Med. 2015;139:1242-7.

58. Malfertheiner P, Ripellino C, Cataldo N. Severe intestinal malabsorption associated with ACE inhibitor or angiotensin receptor blocker treatment. An observational cohort study in Germany and Italy. Pharmacoepidemiol Drug Saf. 2018;27:581-86.

59. De Bortoli N, Ripellino C, Cataldo N, Marchi S. Unspecified intestinal malabsorption in patients treated with angiotensin-converting enzyme inhibitors or angiotensin receptor blockers: a retrospective analysis in primary care settings. Expert Opin Drug Saf. 2017;16:1221-5. 